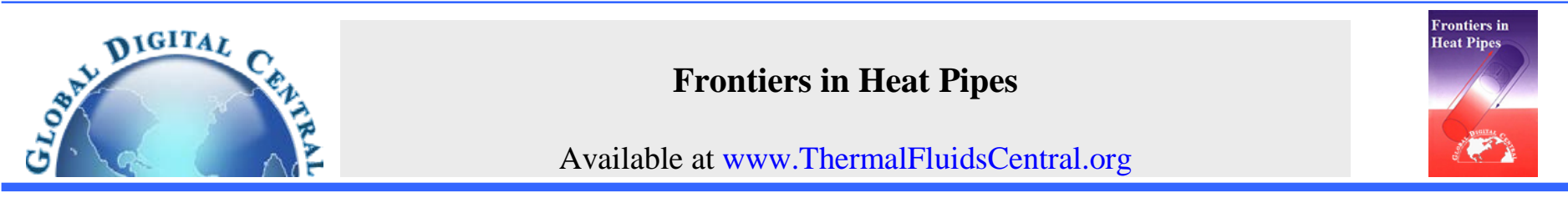

\title{
AXIAL TEMPERATURE DISTRIBUTION AND PERFORMANCE OF R410A AND WATER FILLED THERMOSYPHON AT VARIOUS FILL RATIOS AND INCLINATIONS
}

\author{
K. S. Ong ${ }^{\mathrm{a}^{*}}$, W. L. Tong ${ }^{\mathrm{b}}$, J. S. Gan ${ }^{\mathrm{b}}$ and N. Hisham ${ }^{\mathrm{b}}$ \\ ${ }^{a}$ Universiti Tunku Abdul Rahman, Jalan Universiti, 31900 Kampar, Malaysia \\ ${ }^{b}$ School of Engineering, Monash University Sunway Campus, Jalan Lagoon Selatan, 46150 Bandar Sunway, Malaysia
}

\begin{abstract}
Axial wall temperature distribution of R410a and water filled thermosyphons at various fill ratios and inclination angles are experimentally determined. Power was supplied using resistance band heaters. A water cooled jacket surrounded the condenser section. Power input ranged from $100-830 \mathrm{~W}$. Fill ratios of $0.93,0.66,0.4$ and 0.25 were employed for the R410a pipe and 1.00, $0.75,0.50$ and 0.25 for the water filled pipe. Inclination angles were set at $30^{\circ}, 50^{\circ}, 70^{\circ}$ and $90^{\circ}$. The results showed that the evaporator wall temperature was not uniform especially at high power input, low fill ratios and large inclinations.
\end{abstract}

Keywords: Heat pipe, R410a filled thermosyphon, water filled thermosyphon, inclined, fill ratio.

\section{INTRODUCTION}

Heat pipes are very effective heat transfer devices that are capable of transferring large amounts of heat through long distances without parasitic power for their operation. A two-phase closed thermosyphon is a wickless heat pipe. For simplicity and low cost, thermosyphons are preferred over wicked heat pipes. Thermosyphon heat exchangers have received considerable attention in industrial heat recovery and air conditioning systems and recently as solar collectors. In some air conditioners, the existing system ducting requires the equipment to fit in-line before and after the evaporator coil to act as pre-cool and reheat coils. In this instance, the heat pipe heat exchanger is required to be inclined due to space constraint. During evaporation in inclined thermosyphons, the liquid level in the evaporator section drops leading to liquid film thickness becoming non-axisymmetric. This is accentuated further as tilt angle increases and at low fill ratio. Hence the performance of the inclined single tube thermosyphon needs to be investigated in order to optimise the design of the inclined thermosyphon heat exchanger.

Hahne and Gross (1981) conducted an experimental investigation to observe the effect of inclination on the transport behaviour of a thermosyphon using a $2 \mathrm{~m}$ long $\times 4 \mathrm{~cm}$ ID steel pipe filled with R115. The evaporator section was electrically heated and the condenser watercooled. Experiments were performed with inclinations from $0-90^{\circ}$. The quantity of fill was such that the heating zone was always flooded at all inclinations. Their results showed that the highest heat transport occurred at inclinations of around $50^{\circ}$ to the horizontal.

Nguyen-Chi and Groll (1981) investigated the entrainment or flooding limit in a water filled $20 \mathrm{~mm}$ OD $\times 2.5 \mathrm{~m}$ long copper thermosyphon with fine circumferential grooves at its inner surface. Fill ratio was between $0.38-0.88$, inclination angle from $10-80^{\circ}$ from the horizontal and operating wall temperature between $20-80^{\circ} \mathrm{C}$. The evaporator section was electrically heated and the condenser watercooled. They derived an empirical correlation which allowed the prediction of the maximum performance of the inclined thermosyphon.

Negishi and Sawada (1983) experimentally visually observed the internal boiling and condensing phenomena inside a water and ethanol filled 330mm long $\times 13 \mathrm{~mm}$ ID copper thermosyphon by fitting glass windows at both ends of the pipe. Heating and cooling were provided with hot and cold water jackets. Experiments were performed with fill ratio between $0.05-1.0$, inclination angle between -10 to $90^{\circ}$ to the horizontal and hot water temperature between $25-85^{\circ} \mathrm{C}$. Their results showed that it was necessary to have a fill ratio between $0.25-0.60$ and inclination between $20-40^{\circ}$ for a water filled pipe and $0.40-0.75$ fill ratio and more than $5^{\circ}$ inclination for ethanol filled pipe. They also determined the overall heat transfer coefficient to be between 2.4-3.0 $\times$ $10^{3} \mathrm{~W} / \mathrm{m}^{2} \mathrm{~K}$ for the water filled pipe and between $0.9-1.1 \times 10^{3} \mathrm{~W} / \mathrm{m}^{2}$ $\mathrm{K}$ for ethanol.

Gurses and Cannistraro (1991) employed a finned water-cooled condenser wicked heat pipe for solar energy applications using $15 \mathrm{~mm}$ ID $\times 18 \mathrm{~mm}$ OD $\times 1930 \mathrm{~mm}$ long copper pipe filled with $28 \mathrm{cc}$ of distilled water. They concluded that the performance depended upon inclination angle with the maximum in the vertical position. For effective solar operation, the inclination angle should be between 45$90^{\circ}$.

Zuo and Gunnerson (1995) presented a numerical model for a thermosyphon which considered the effects of dry-out and flooding in the upper portion of the evaporator section at low fill ratio for large diameter pipes (low aspect ratio) when inclined. Their predictions compared well with experimental data of other studies.

Shiraishi et al. (1996) correlated the critical transfer rate in an inclined thermosyphon by introducing a modified Kutateladze number. They employed six stainless tubes with 14 and $21 \mathrm{~mm}$ ID of varying lengths to give aspect ratios of 11, 22 and 32. Fill liquids were

*Corresponding author.Email: skong@utar.edu.my 
fluorinert (FC72), freon (R113), alternative freon (DF123), ethanol and water.

Terdtoon et al. (1996) investigated the effect of aspect ratio and Bond number on heat transfer characteristics of an inclined thermosyphon at normal operating condition using 9.5, 11.1 and $25.4 \mathrm{~mm}$ ID copper tubes with $\mathrm{R}-22$, ethanol and water at 0.80 fill ratio and inclination angles between $0-90^{\circ}$. Heating and cooling were provided with hot and cold water jackets at the evaporator and condenser sections. Evaporator temperature was maintained at $10^{\circ} \mathrm{C}$. Various combinations of tube diameter and length resulted in aspect ratios of $5,10,20,30$ and 40 . Their results showed that there was a range of optimum inclinations $\left(40-70^{\circ}\right)$ over which the thermosyphons exhibited better performances than when in a vertical position. The optimum inclination was dependent upon the aspect ratio.

Said and Akash (1999) showed that a wicked water filled heat pipe performed better than one without at inclinations of 30, 60 and $90^{\circ}$.

Payakaruk et al. (2000) determined the effects of Bond number, Froude number, Weber number and Kutaladze number on the heat transfer characteristics of inclined thermosyphon using 7.5, 11.1 and 25.4mm ID copper tubes. Fill liquids were R-22, R123, R134a, ethanol and water at fill ratios of $0.50,0.80$ and 1.0. Inclination angles were between $0-90^{\circ}$ and aspect ratios from $5,10,20,30$ and 40 . Heating and cooling were carried out using hot and cold water jackets at the evaporator and condenser sections. Saturation vapor temperature ranged from $0-30^{\circ} \mathrm{C}$. Their results showed that the type of fill liquid affected the results but not the filling ratio.

Shalaby et al. (2000) experimentally investigated the heat transfer performance of a thermosyphon using a smooth $21 \mathrm{~mm}$ ID $\times 1500 \mathrm{~mm}$ long copper tube with R22 as working fluid. Electrical heating and cooling water jacket were used. Fill ratio was kept to between $0.30-1.0$, inclination angle between $22.5-90^{\circ}$ and power input varied from 100$300 \mathrm{~W}$. They found that the optimum filling ratio was 0.50 and best inclination was $30^{\circ}$.

Nitipong et al. (2000) predicted the performance limit of a thermosyphon by assuming that dryout and flooding greatly influenced the performance limit. They correlated their predictions with experimental data from other researchers using R113 and R123 as working fluids to $\pm 25 \%$.

Joudi and Witwat (2000) improved on the performance of a thermosyphon by adding a separator in the adiabatic section and adding on a three-layered wick in the evaporator section of three lengths of $20 \mathrm{~mm}$ ID copper pipe filled with water. Evaporator and condenser lengths were kept constant at 10 and $150 \mathrm{~mm}$ while adiabatic lengths varied at 100, 300 and $700 \mathrm{~mm}$. Electrical heating ranged from 5-32 $\mathrm{kW} / \mathrm{m}^{2}$. Condensing was by a cooling water jacket. Various fill ratios and inclinations were used. Their experiments showed that the presence of an adiabatic separator caused a marked improvement in all the heat pipes.

Loh et al. (2005) conducted a comparative study on heat pipe performance with three different wick structures (groove, mesh and sintered metal powder) in 4,5 and $6 \mathrm{~mm}$ OD pipes subjected to orientation angles from -90 to $+90^{\circ}$ and at varying powers up to $30 \mathrm{~W}$. Their results showed that orientation had less impact on the sintered metal powder heat pipe compared to the others. Generally, performances depended upon pipe diameter, wick material and inclinations.

Noie (2005) investigated the heat transfer characteristics of a thermosyphon using a $25 \mathrm{~mm}$ ID $\times 980 \mathrm{~mm}$ long copper tube filled with water and fill ratios between 0.30 and 0.90 . Heating was provided with electrical resistance wire and cooling by a water-cooled jacket. By varying the length of heating wire, aspect ratios were kept at 7.45, 9.80 and 11.8. He showed that the wall axial temperature distribution was almost uniform especially at the lower power inputs and that that maximum heat transfer rate at each aspect ratio occurred at different filling ratios.

Ong et al. (2008) investigated the heat transfer characteristics of a $32 \mathrm{~mm}$ ID $\times 842 \mathrm{~mm}$ long copper thermosyphon filled with R134a at fill ratio of 0.50 and 0.70 and $\mathrm{R} 410 \mathrm{a}$ at fill ratio of 0.50 inclined at 45,60 , 75 and $90^{\circ}$. Heating was provided with electrical band resistance heaters and cooling by a water-cooled jacket. Power input varied from 100-500 W. They showed that the wall axial temperature distribution was more uniform at the lower power inputs. By assuming average wall temperatures at both evaporating and condenser sections, they determined the average overall thermal resistance to be $0.060 \mathrm{~K} / \mathrm{W}$ for both cases.

Mozumder et. al. (2010) conducted experiments on a miniature $5 \mathrm{~mm}$ ID $\times 150 \mathrm{~mm}$ long heat pipe using water, methanol and acetone at $0.35,0.55,0.85$ and 1.0 fill ratio and with power inputs up to $10 \mathrm{~W}$. They found that in the case of water and methanol filled pipes, fill ratio had minimum effect on performance while for the acetone filled pipe best performance was obtained at fill ratio of 1.0. They further concluded that fill ratios greater than 0.85 showed better results in general.

The performance of a water filled thermosyphon was investigated by Ong and Tong (2011) at fill ratios between 0.25 and 1.0 inclined at $30-90^{\circ}$. Power input varied from 300-830W using electrical band resistance heaters and a water-cooled jacket. They determined the average overall thermal resistance to be $0.017 \mathrm{~K} / \mathrm{W}$.

Not much work was found in the literature using R410a as fill liquid. The difference in performance between R134a and R410a filled thermosyphons was investigated by Ong (2011) at fill ratios from 0.50.7 and at inclinations from $45-90^{\circ}$. Water coolant flowrate was kept as high as possible to maintain a constant condenser wall temperature. It was shown that the overall thermal resistances for both the R134a and the R410a filled thermosyphons were about $0.060 \mathrm{~W} / \mathrm{m}^{2} \mathrm{~K}$.

From the literature review it could be concluded that the performance of a thermosyphon depended upon type of fill liquid, fill ratio, aspect ratio and power input. Past investigations have shown that while the wall temperatures in the evaporator and condenser sections are uniform in some cases they are non uniform in others. This is due to the very complex nature of the boiling process in the thermosyphon. As a result, the thermal resistance of the thermosyphon would be affected. The objective of this paper is to determine the axial wall temperature distribution and its effect on the overall thermal resistance of a R410a and a water filled thermosyphon at various fill ratios and inclinations.

\section{EXPERIMENTAL INVESTIGATION}

The thermosyphon shown in Figure 1 was fabricated from a 38mm O/D $\times 32 \mathrm{~mm} \mathrm{I} / \mathrm{D} \times 760 \mathrm{~mm}$ long copper pipe. A 71mm I/D PVC pipe water cooled jacket arrangement with inlet and outlet hose connections surrounded the condenser section. Evaporator, adiabatic and condenser sections were 390, 90 and 327mm long, respectively. Aspect ratio (evaporator section length/pipe diameter) was about 12.2. Four electrical band heaters each capable of providing $250 \mathrm{~W}$ was attached around the evaporator section. Power (P) to the band heaters was regulated using an auto-transformer and measured using laboratory standard voltmeter and ammeter. The thermosyphon was insulated all round with $50 \mathrm{~mm}$ thick rockwool. Details of the thermosyphon and locations of type $\mathrm{T}$ thermocouples are shown in Figure 1.

The experimental set up is shown in Figure 2. Thermocouples were mechanically attached to the surface of the thermsyphon by binding wire. The thermocouples on the condenser wall section inside the water jacket were provided with water-proof tape over the binding wire in order to insulate them from the cooling effect of the water stream on the readings. Thermocouples were also attached to the inlet and outlet sections of the water jacket. Saturation temperature was measured with a type $\mathrm{T}$ thermocouple probe inserted about $150 \mathrm{~mm}$ inside the thermosyphon. Saturation pressure was noted on a compound pressure gauge. The pressure gauge had a manufacturer's accuracy rating of $3 \%$ of full scale reading. It was only used to indicate and to give a visual warning if the thermosyphon was leaking. Coolant water was from mains supply and the flow rate was kept as high as possible, at about $0.0867 \mathrm{~kg} / \mathrm{s}$ in order to maintain a near-uniform condenser 
temperature. It was measured with a float-in-glass type flow meter with an instrument quoted accuracy of $\pm 2 \%$. There was no control over the coolant inlet temperature which varied between $27-29^{\circ} \mathrm{C}$.

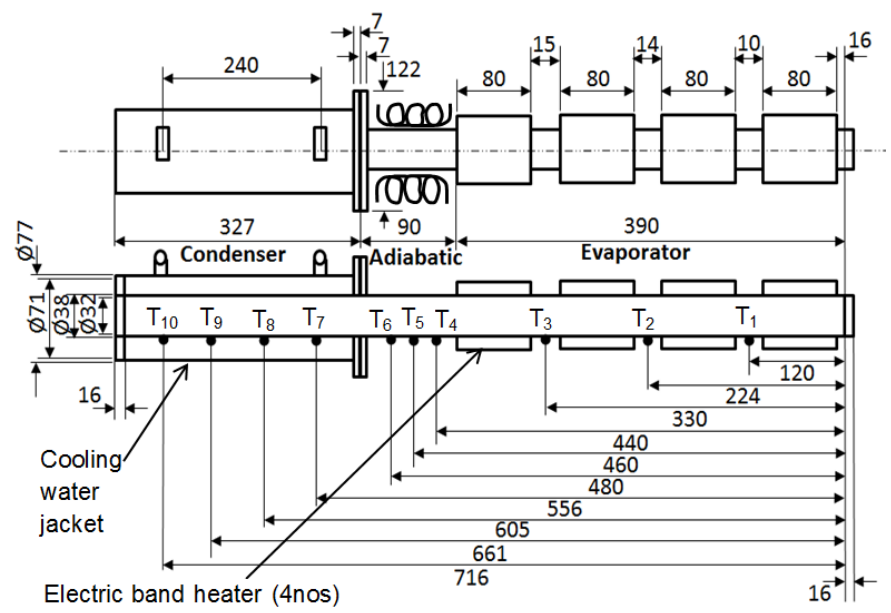

Fig. 1 Details of thermosyphon.

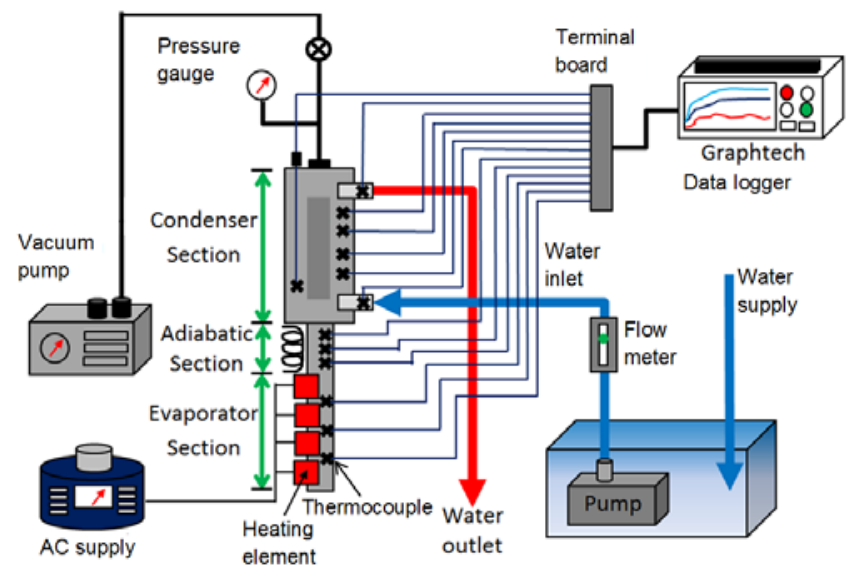

Fig. 2 Experimental set-up.

Experiments were conducted with the thermosyphon first filled with water and then with R410a. Input power was varied between 100 400W for the R410a filled pipe and 304-830W for the water filled pipe resulting in heat fluxes from $2.6-10.2 \mathrm{~kW} / \mathrm{m}^{2}$ and $7.8-21.2 \mathrm{~kW} / \mathrm{m}^{2}$, respectively. Fill ratios (FR) were kept at $0.93,0.66,0.40$ and 0.25 for the R410a filled pipe and 1.00, 0.75, 0.50 and 0.25 for the water filled pipe. Fill ratio (FR) is defined as the ratio of the volume of fill liquid to the evaporator section volume. The thermosyphons were tested inclined at angles $(\theta)$ from 30, 50, 70 and $90^{\circ}$ to the horizontal. Saturation temperature taken from standard saturation pressure-temperature tables were compared with measured values. The comparison was within $+1^{\circ} \mathrm{C}$. Each run was repeated 5 times in order to check for repeatability. It was found that the temperatures obtained were repeatable to within $\pm 1^{\circ} \mathrm{C}$. Average values were then calculated from the 5 runs and utilised to plot the results.

\section{EXPERIMENTAL RESULT}

Since the coolant water mass flow rate was kept high, the temperature difference between coolant inlet and outlet temperatures was small, of the order of a few ${ }^{\circ} \mathrm{C}$. Thus it was not possible to calculate accurately the heat rejected to the coolant water. In this paper, the thermosyphon was assumed perfectly insulated and power output was assumed equal to the electrical power input.

\subsection{Axial Wall Temperature Distribution along R134a-filled Thermosyphon}

Typical axial wall temperature distribution for the R410a filled thermosyphon at various power inputs and fill ratio of 0.93 are shown in Figure 3 for the vertical thermosyphon and in Figure 4 for the $30^{\circ}$ inclined case. Results for fill ratio of 0.25 and $90^{\circ}$ and $30^{\circ}$ inclinations are shown in Figures 5 and 6, respectively. The results generally show that evaporator wall temperature increased with power input, as expected. The condenser wall temperatures also increased but to a lesser extent. Hence the temperature difference between evaporator and condenser section walls increased with power input. Contrary to what most researchers assume, the wall temperature distribution is not uniform especially at low fill ratios and large inclinations. Figure 3 for the vertical thermosyphon with high fill ratio of $\mathrm{FR}=0.93$ shows that the evaporator wall temperature was highest at the bottom and decreased gradually towards the adiabatic section. This was followed by a sharp drop in the adiabatic section and then a gradual decrease in the condenser section towards the top end of the pipe. For the same high fill ratio but at a greater inclination of $30^{\circ}$, Figure 4 shows that evaporator wall temperature first increased and then decreased along the pipe. This was more noticeable at high power input and low inclination.

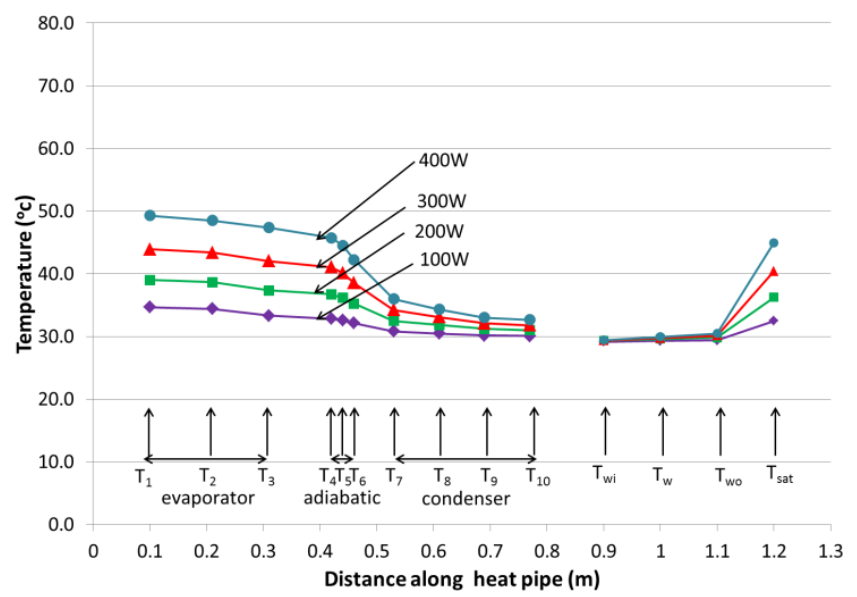

Fig. 3 Axial temperature distribution (R410a, FR $=0.93, \theta=90^{\circ}$ ).

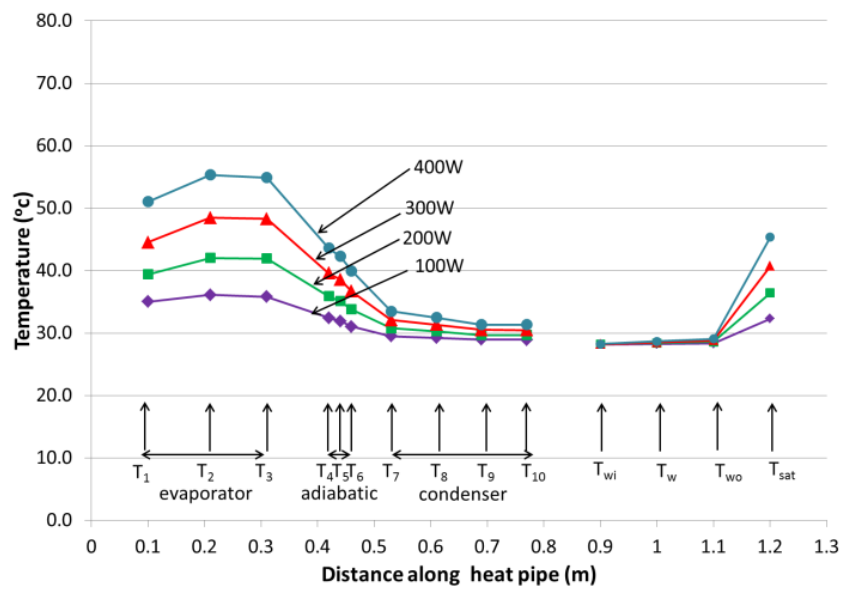

Fig. 4 Axial temperature distribution $\left(\mathrm{R} 410 \mathrm{a}, \mathrm{FR}=0.93, \theta=30^{\circ}\right)$.

At low fill ratio, Figure 5 for the vertical thermosyphon show that the temperature declined from the bottom of the pipe towards the adiabatic and condenser sections especially at the high power inputs. 


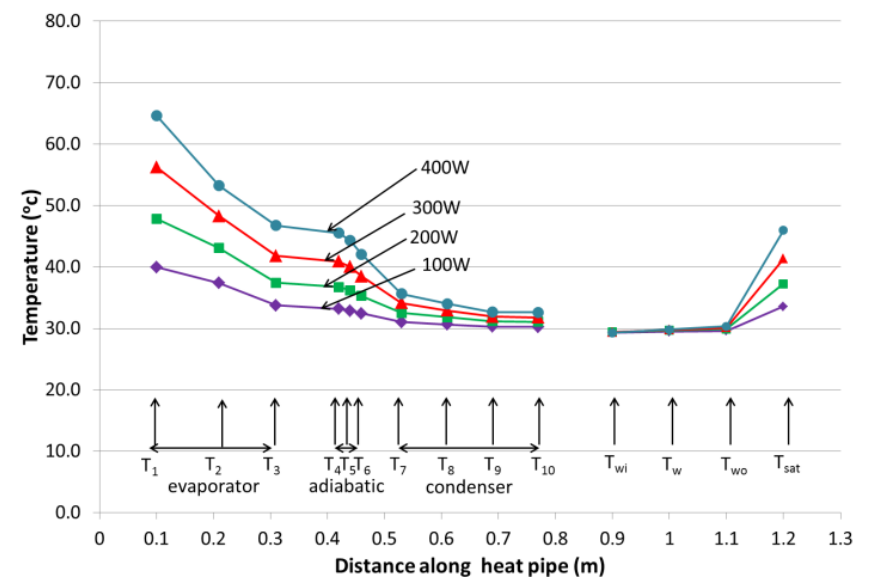

Fig. 5 Axial temperature distribution (R410a, $F R=0.25, \theta=90^{\circ}$ ).

Figure 6 show that at the low power input of 100W, the evaporator and condenser sections exhibited near uniform temperature distribution. The results show that dry out could have possibly occurred at the high temperature case normally associated with high power input, although it is not conclusive without visual observation. None-the-less, it would be quite correct to say that the axial wall temperature is uniform at low input power and for small fill ratios.

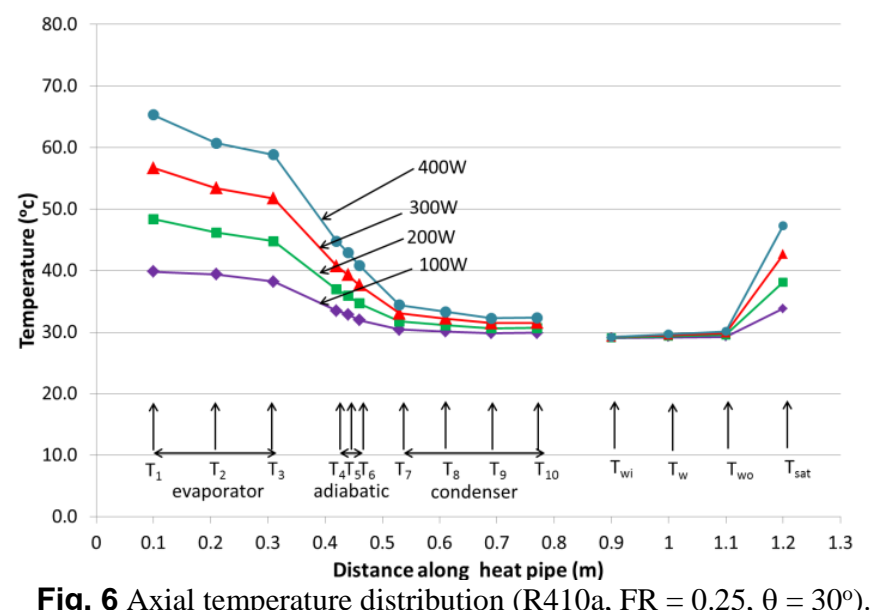

As the thermosyphon is tilted from left to right, the liquid level on the left (top) and right (under) sides of the evaporator section of the pipe adjusts itself according to gravity. The thermocouples are mechanically attached to the left hand side of the evaporator section as shown in Figure 7. As the inclination increases, the liquid level rises towards the adiabatic section as illustrated in Figure 7. The immersion length and also the downward flowing liquid film thickness become non-axisymmetric and the heat transfer mechanism becomes more complicated. This makes the process of evaporation and condensation more complicated. Zuo and Gunnerson [5] considered this effect in their theoretical model. We would expect that as the inclination increases, dry out would more likely to occur on the right hand side of the thermosyphon.

\subsection{Axial Wall Temperature Distribution along Water-filled Thermosyphon}

Typical axial wall temperature distribution for the water filled thermosyphon are shown in Figure 8 for fill ratio of 1.00 and $90^{\circ}$ inclination and in Figure 9 for fill ratio of 0.25 and $30^{\circ}$ inclination. Similar trends are observed. The experiments were performed at power inputs greater than those for the R134a thermosyphon. The axial wall temperature distribution is non-uniform and decreased towards the top of the pipe. There was no temperature peak in the evaporator section as was noticed in the R134a filled pipe even though at the high power inputs. Dry out was noticed at the bottom of the pipe. At low fill ratio, Figure 9 shows that the highest temperature was observed to occur at the bottom of the pipe while the upper portion of the evaporator exhibited a near uniform temperature.

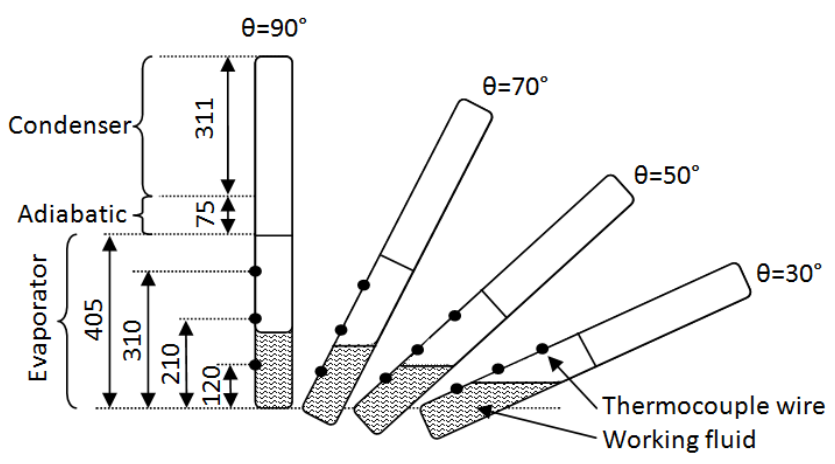

Fig. 7 Liquid level in thermosyphon with inclination (R410a, FR = $0.25)$.

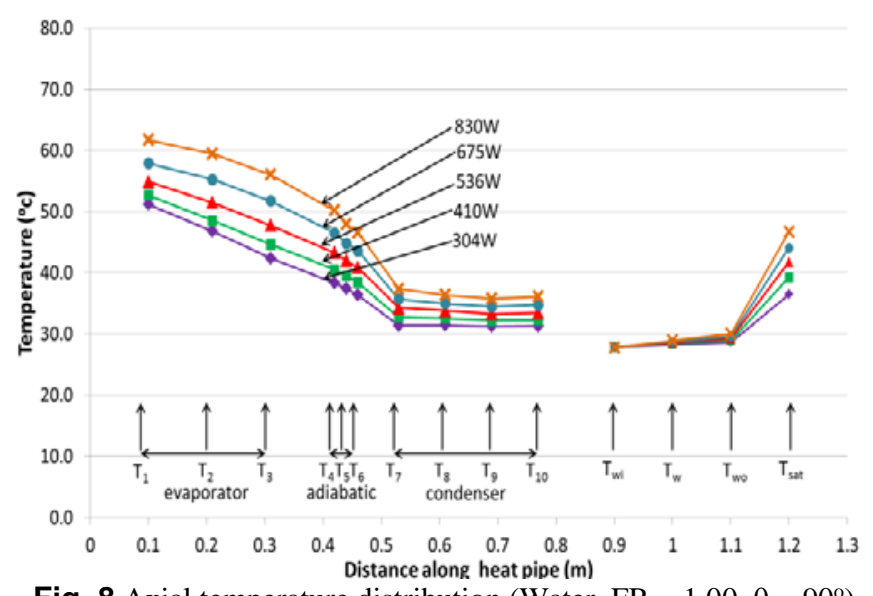

Fig. 8 Axial temperature distribution (Water, FR $=1.00, \theta=90^{\circ}$ ).

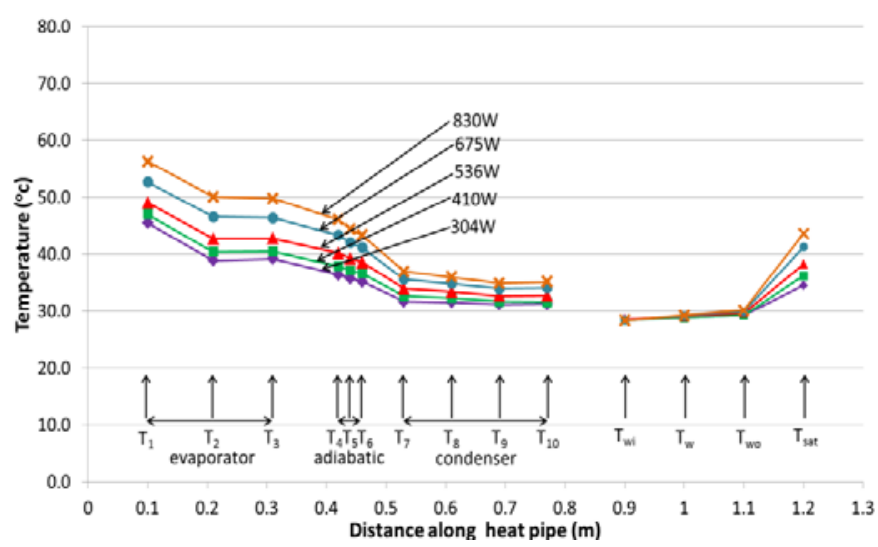

Fig. 9 Axial temperature distribution (Water, $\mathrm{FR}=0.25, \theta=30^{\circ}$ ).

\subsection{Performance of Thermosyphons}

In order to compare the thermal performance of the thermosyphons at different fill ratios and inclinations, power output (P) was plotted against calculated mean operating temperature difference in Figures 10-13 for the R410a thermosyphon and in Figures 14-17 for the water filled unit. Since in some cases, the wall temperature were not uniform, a mean temperature difference $(\Delta \mathrm{T})$ was obtained by taking the difference between the average evaporator $\left(\mathrm{T}_{\mathrm{e}}\right)$ and condenser 
temperature $\left(\mathrm{T}_{\mathrm{c}}\right)$. As previously discussed, the axial wall temperature distribution depended upon power input, fill ratio and inclination. The calculated mean evaporator wall temperature was calculated by taking the average of the three thermocouples in the evaporator section. For the R410a-filled thermosyphon, the evaporator temperature varied from $1^{\circ} \mathrm{C}$ (Figure 3) to $9^{\circ} \mathrm{C}$ (Figure 4). For the water-filled thermosyphon, the evaporator temperature varied from $5^{\circ} \mathrm{C}$ (Figure 8) to $6^{\circ} \mathrm{C}$ (Figure 9). As a result of non-uniform wall evaporator and condenser wall temperatures, this can only give us an indication of how the thermosyphons behaved when compared with each other. Linear regression lines of $\mathrm{P}=\mathrm{a} \Delta \mathrm{T}+\mathrm{c}$ were then obtained and shown in Table 1. For the R410a thermosyphon, regression coefficients above 0.99 were obtained while it was above 0.95 for the water filled unit.

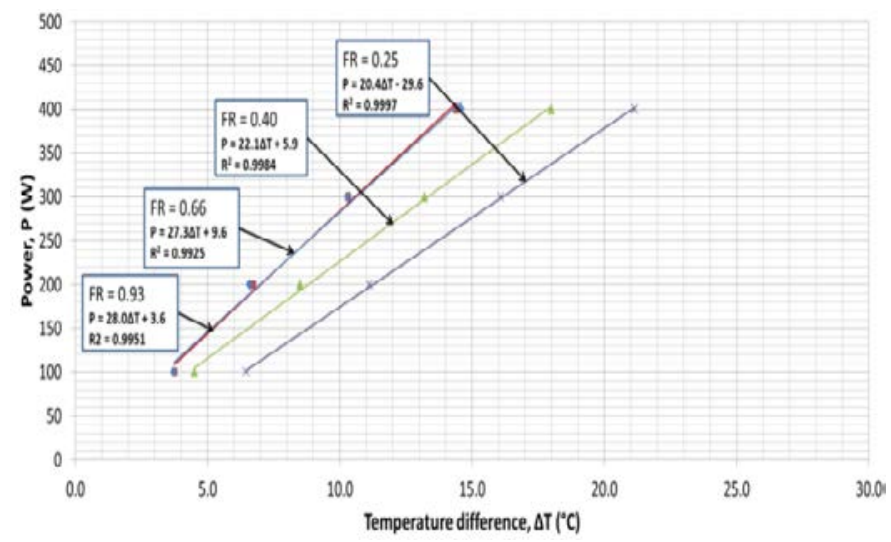

Fig. 10 Effect of fill ratio at $90^{\circ}$ inclination (R410a).

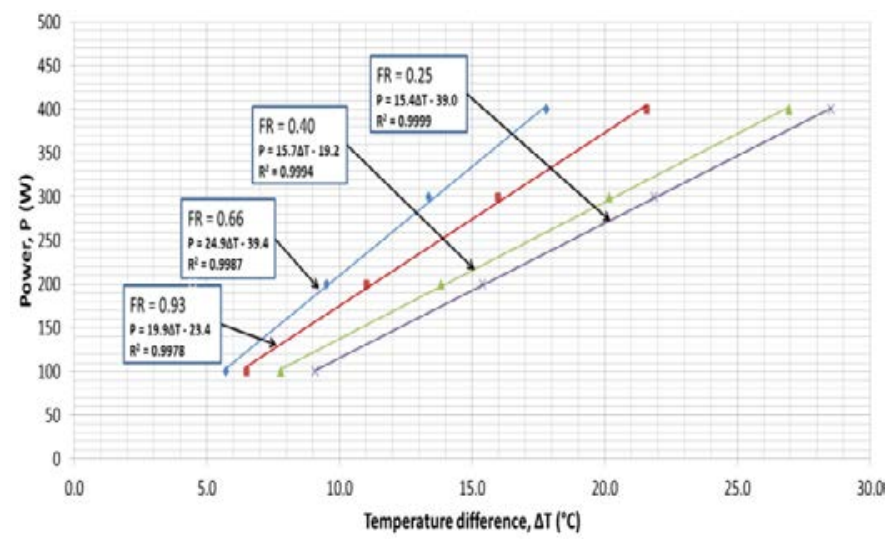

Fig. 11 Effect of fill ratio at $30^{\circ}$ inclination (R410a).

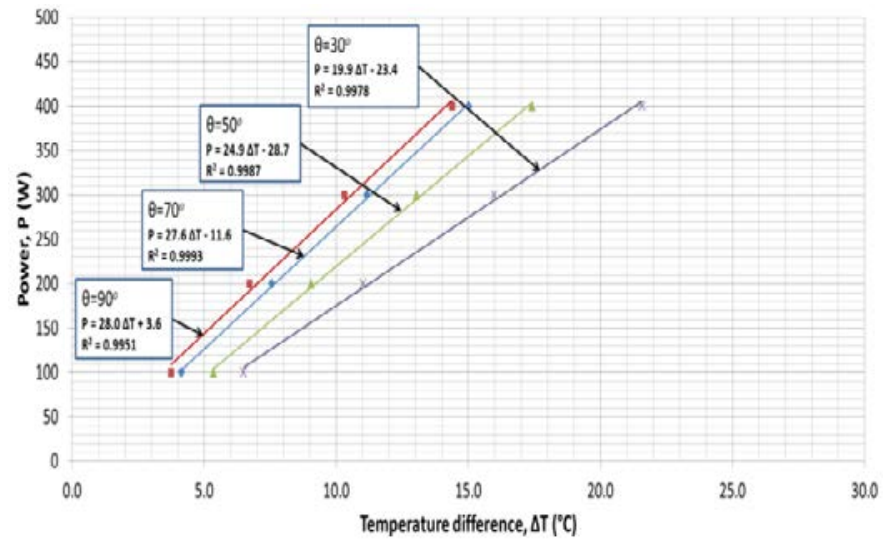

Fig. 12 Effect of inclination with FR = 0.93 (R410a).

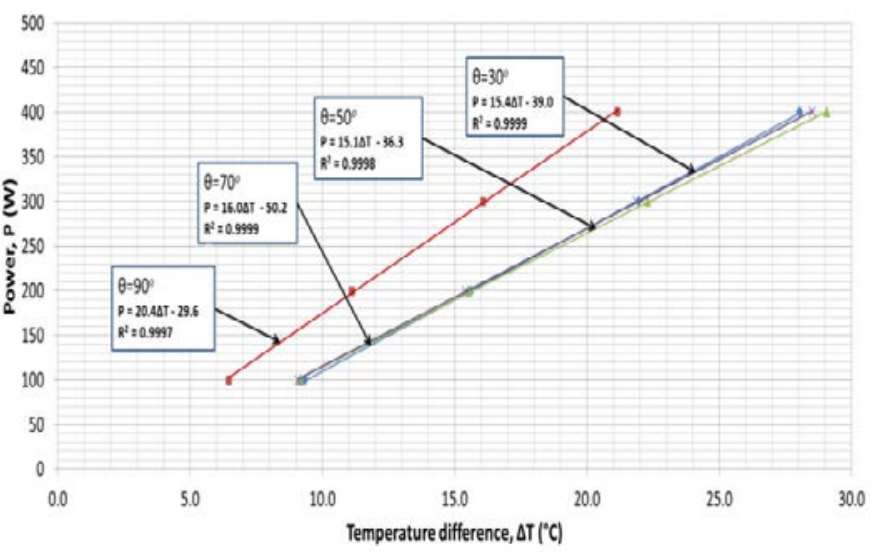

Fig. 13 Effect of inclination with $F R=0.25$ (R410a).

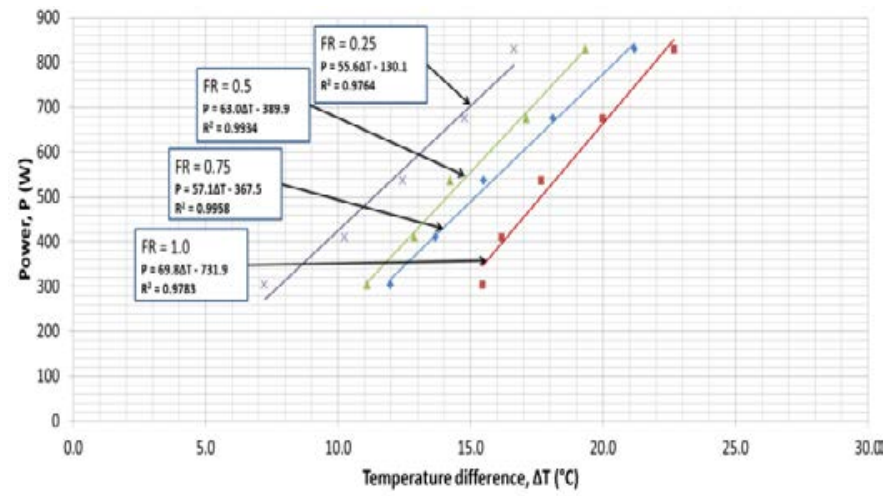

Fig. 14 Effect of fill ratio at $90^{\circ}$ inclination (water).

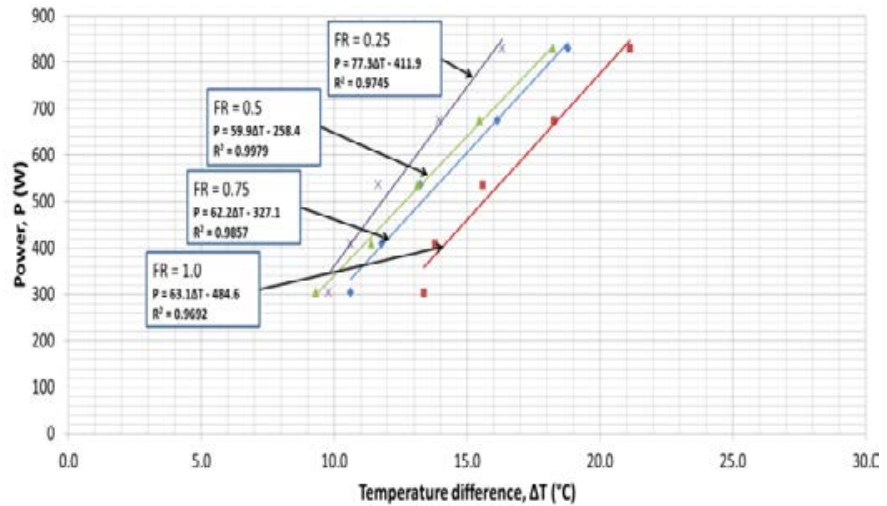

Fig. 15 Effect of fill ratio at $30^{\circ}$ inclination (water).

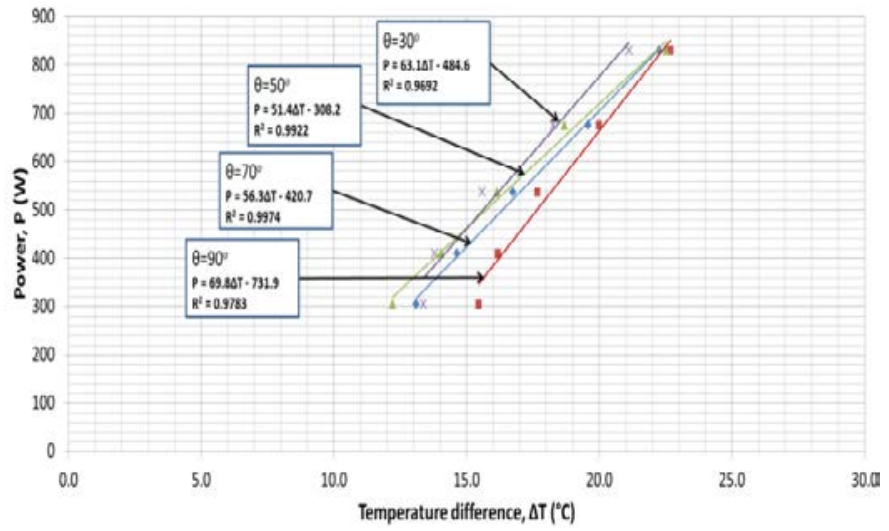

Fig. 16 Effect of inclination with FR = 1.00 (water). 


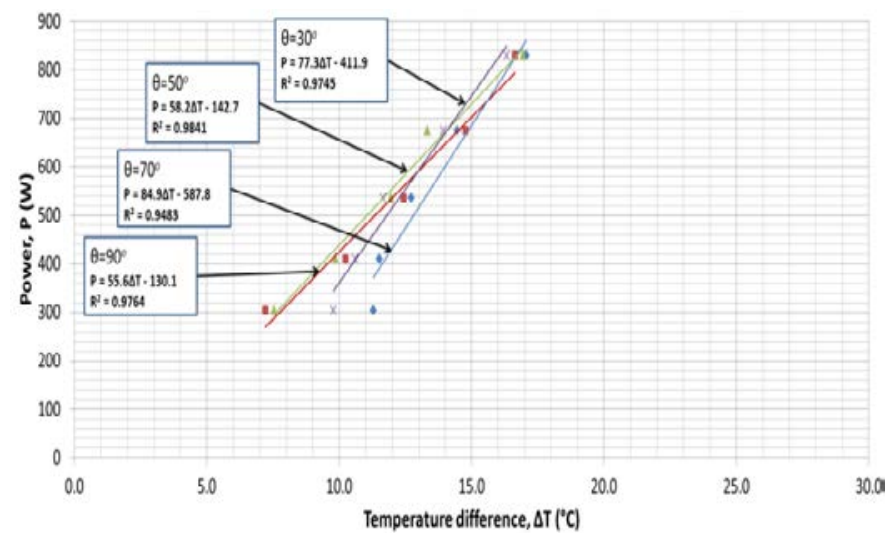

Fig. 17 Effect of inclination with $\mathrm{FR}=0.25$ (water).

Table 1 Linear regression coefficient from experimental results.

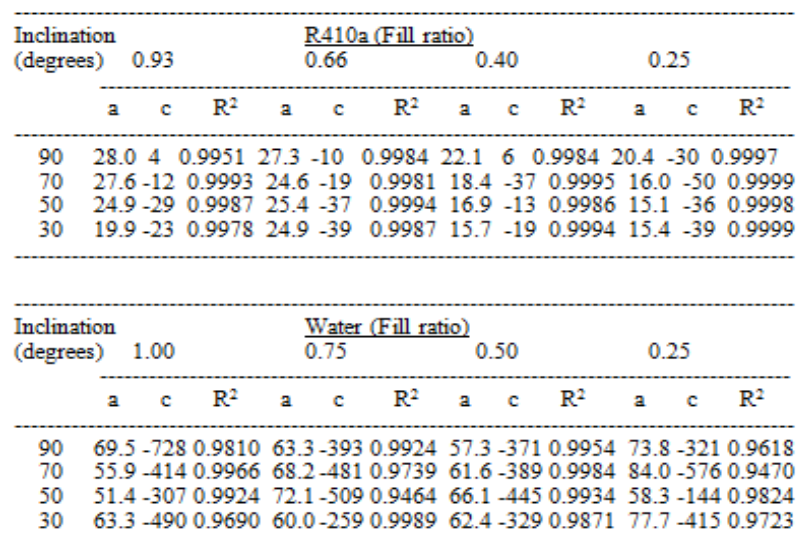

The effect of fill ratio for the R410a pipe at $90^{\circ}$ and $30^{\circ}$ inclinations are shown in Figures 10 and 11. Figure 10 shows that the 0.93 and 0.66 fill ratio R140a thermosyphons performed equally well when operated in the vertical position. When tilted at $30^{\circ}$, Figure 11 indicates that the 0.66 fill ratio thermosyphon performed better than the 0.93 unit especially at high power input. The difference in operating temperature difference was only at $1.0^{\circ} \mathrm{C}$ at $100 \mathrm{~W}$ and $3.5^{\circ} \mathrm{C}$ at $400 \mathrm{~W}$. At $30^{\circ}$ inclination and at $400 \mathrm{~W}$, the operating temperature difference was about $7^{\circ} \mathrm{C}$.

The effect of inclination with fill ratios of 0.93 and 0.25 are shown in Figures 12 and 13. The results show that R410a thermosyphons performed better in the vertical position. Similar fill ratio and inclination effects are shown in Figures 14-17 for the water filled thermosyphon. However, in contrast with the R410a filled thermosyphon, the results showed that low fill ratio and inclined water filled pipes performed better than higher filled vertical ones.

\section{CONCLUSIONS}

The performance of R410a and water filled thermosyphons were investigated under various fill ratios and inclinations. The following conclusions were drawn:

- Axial wall temperature distribution was not uniform and depended upon power input, fill ratio and inclination as was noticed in some cases by previous investigators.

- Thermosyphon wall temperature increased with increasing input power.

- Dry out could have easily occurred in the case of high power inputs, low fill ratios and high inclinations.

- The R410a filled thermosyphon performed better in the vertical position at all fill ratios.

- The water filled thermosyphon performed better at low fill ratio and when inclined.

\section{ACKNOWLEDGEMENTS}

Thanks are extended to OYL R \& D Sdn. Bhd. for their assistance in providing the R410a refrigerant and technical expertise.

\section{REFERENCES}

Gurses, A.C. and Cannistraro, L.T., 1991, "The Inclination Effect on the Performance of Water-filled Heat Pipes," Renewable Energy, 1, 667-674.

http://dx.doi.org/10.1016/0960-1481(91)90012-E

Hahne, E. and Gross, U., 1981, "The Influence of the Inclination Angle on the Performance of a Closed Two-phase Thermosyphon," Heat Recovery System, 1, 267-274.

http://dx.doi.org/10.1016/0198-7593(81)90037-0

Joudi, K. and Witwat, A.M., 2000, "Improvements of Gravity Assisted Wickless Heat Pipes," Energy Conversion and Management, 41, 20412061.

http://dx.doi.org/10.1016/S0196-8904(00)00003-0

Loh, C.K., Harris, E. and Chou, D.J., 2005, "Comparative Study of Heat Pipes Performances in Different Orientations," 21st IEEE SemiTherm Symposium.

Mozumder, A.K., Akon, A.F., Chowdury, M.S.H. and Banik, S.C., 2010, "Performance of Heat Pipe for Different Fluids and Fill Ratios," Journal of Mechanical Engineering, ME41, Trans. Mech. Eng. Div., Institution of Engineers, Bangladesh, 96-102.

Negeshi, K. and Sawada, T. 1983, "Heat Transfer Performance of an Inclined Two-phase Closed Thermosyphon,” International Journal Heat Mass Transfer, 26, 1207-1213.

http://dx.doi.org/10.1016/S0017-9310(83)80175-6

Nguyen-Chi, H. and Groll, M., 1981, " Entrainment or Flooding Limit in a Closed Two-phase Thermosyphon," Heat Recovery System, 1, 275-286.

http://dx.doi.org/10.1016/0198-7593(81)90038-2

Nitipong, S., Terdtoon, P., Tantakom, P. and Polchai, A., 2000, "A Performance Limit Model of an Inclined Two-phase Closed Thermosyphon,” Proceedings 6IHPS, Thailand, 258-267.

Noie, S.H., 2005, "Heat Transfer Characteristics of a Two-phase Closed Thermosyphon," Applied Thermal Engineering, 25, 495-506. http://dx.doi.org/10.1016/j.applthermaleng.2004.06.019

Ong, K.S., Tung, A. and Tan, A.H., 2008, "Evaporating and Condensing Heat Transfer Coefficients in R134a and R410 Filled Thermosyphon at Low Temperatures," Proceedings 9IHPS, Malaysia, 107-115.

Ong, K.S. and Tong, W.L., 2011, "Inclination and Fill Ratio Effects on Water Filled Two-phase Closed Thermosyphon," Proceedings 10IHPS, Taiwan.

Ong, K.S., 2011, "Effects of Inclination and Fill Ratio on R134a and R410a Thermosyphon," Journal of Energy Heat and Mass Transfer, 33, 143-152.

Payakaruk, T., Terdtoon, P. and Ritthidech, S., 2000, "Correlations to Predict Heat Transfer Characteristics of an Inclined Closed Two-phase Thermosyphon at Normal Operating Conditions," Applied Thermal Engineering, 20, 781-790.

http://dx.doi.org/10.1016/S1359-4311(99)00047-2

Said, S.A. and Akash, B.A., 1999, "Experimental Performance of a Heat Pipe," International Communication Heat Mass Transfer, 26, 679684.

http://dx.doi.org/10.1016/S0735-1933(99)00054-8 
Shalaby, M.A., Araid, F.F., Sultan, G.I. and Awad, M.M., 2000, "Heat Transfer Performance of a Two-phase Closed Thermosyphon," Proceedings 6IHPS, Thailand, 269-278.

Shiraishi, M., Kim, Y.I., Murakami, M., and Terdtoon, P., 1996, "A Correlation for the Critical Heat Transfer Rate in an Inclined Twophase Closed Thermosyphon," Proceedings 5IHPS, Australia, 248-254.
Terdtoon, P., Ritthide, S. and Shiraishi, M., 1996, "Effect of Aspect Ratio and Bond Number on Heat Transfer Rate in an Inclined Twophase Closed Thermosyphon," Proceedings 5IHPS, Australia, 248-254.

Zuo, Z.J. and Gunnerson F.S., 1995, "Heat Transfer Analysis of an Inclined Two-phase Closed Thermosyphon,” Journal Heat Transfer, 117, 1073-1075.

http://dx.doi.org/10.1115/1.2836287 